\title{
가족친화지원사업의 시행현황과 개선방안 \\ The Analysis of the Current Conditions of and Suggestions for Family Friendly Support Services
}

가톨릭대학교 소비자주거학전공

교 수 정 영 금*
가족친화지원센터
본 부 장 조 성 은
동센터 컨설팅지원
팀 장 안 재 희
동센터 친화사업
팀 장 김 지 수

Dept. of Consumer \& Housing Studies, Catholic Univ.

Professor : Jeong, Young-Keum

Family Friendly Support Center General Manager : Cho, Seong-Eun

Consulting Support

Team Manager : Ahn, Jae-Hee Project Support

Team Manager : Kim, Ji-Su

\section{$<$ Abstract $>$}

This study aims to suggest the alternative policies and practices which policy makers can introduce and enlarge for work-family balance of employees. For purpose, this study analyzed the regulation of work time and parental leave benefits of employees. And the results of major projects in family friendly support services were examined.

Based on these assessment, this study suggested various flexible work arrangements, papa's quota system in parental leaves, various family leaves for family care, establishment of FFSC in every metropolitan area, diversification of consulting project, and enlarging of certification project on family friendly workplace.

A주제어(Key Words) : 건강가정기본계획(plan for health family), 가족정책(family policy), 일-가정 양립지원정책(policy for work-family balance), 가족친화지원사업(family friendly support services), 가족친화지원센터(family friendly support center)

\footnotetext{
* Corresponding Author: Jeong, Young-Keum, Department of Consumer \& Housing Studies, Catholic University, Tel: 02-2164-4308 E-mail: jeongyk@catholic.ac.kr
} 


\section{I . 서론}

일하는 부모를 위한 일-가정 양립지원정책들이 많이 만들 어지고 시행되고 있으나 여전히 대다수의 여성 근로자들이 혜택을 보기에는 역부족이다. 이는 일-가정 양립지원정책을 펴는 기업들이 대부분 대기업이나 공공기관으로 중소기업 특히 여성근로자들에 대한 근무 조건이 상대적으로 열악한 곳이 여전히 존재하며, 또한 기초적인 제도들만 우선적으로 시행되다보니 다양한 가정의 상황과 요구를 충족시키지 못 하고 있다. 이는 먼저 여성가족부에서 시행하고 있는 가족친 화인증 기업 현황을 통해서 나타나고 있다. 즉 인증기업의 현황(152개소, 2008 2011)을 보면, 300인 이상 대기업 및 공 공기관(124개소, $81.6 \%)$ 이 다수이며, 직원 규모 100 인 이하 기업은 28 개소( $18.4 \%)$ 로 가족친화제도 확산이 미흡한 실정 이다(Lee, 2012). 또한 국내 공공기관과 민간기업 1,500곳 대 상으로 가족친화제도의 도입과 활용정도를 조사한 결과 (Ministry of Gender Equality and Family, 2012) 전체 평 균 58.9점 이상인 곳은 공공기관(63.6점), 1,000 인 이상 규모 의 기업(72.2점)으로 일-가정 양립지원제도는 공공기관과 대 기업중심으로 이루어졌음을 확인할 수 있다.

그러는 가운데 우리나라 가정의 출산율은 여전히 제자리 걸음을 하고 여성의 혼인연령은 계속 증가하며 맞벌이가정 은 계속 어려움을 겪고 있다. 또한 고령화사회의 가속화로 인해 가정이 부담해야 하는 돌봄의 부담은 커지고 있으며 가 족들의 고용상태도 개선되지 못하고 있다. 제 2 차 저출산 - 고 령사회 기본계획(Government of the Republic of Korea, 2011)에서는 저출산 · 고령화의 파급영향으로 먼저 노동공 급 감소와 노동력의 질 저하, 저축 - 투자·소비 위축 등에 따라 경제 전반의 활력이 저하되고 성장 잠재력 약화를 초래 할 것으로 전망했다. 즉 생산가능인구의 감소로 노동공급이 '15년 63만명, '20년 152만명 부족할 것이며, 현재 추세가 지 속되면 젊은층의 노인 부양부담이 감당하기 어려운 수준으 로 증가할 것으로 전망했다. 즉, 노인 1 명당 생산가능인구는 '07년 7.0명에서 '20년 4.6명, '50년 1.4명으로 급격히 줄어들 것이라는 것이다. 또한 잠재성장률은 ' 00 년대 $4,6 \%$ 에서 '20 년대 $3.7 \%$, '40년대 $1.4 \%$ 로 계속 하락할 전망이다.

통계청이 발표한 2012년 3분기 지역별 고용조사(2012)에 의하면, 맞벌이가구비율은 전체 유배우가구의 $43.5 \%$ 를 차지 하며 40-50대 가구의 경우에 높았다. 그러나 연령대별 경력 단절여성비율을 보면 15-29세의 경우에 $36.3 \%$ 로 가장 높았 다. 또한 경력단절사유도 40-50대에 비해서 20-30대는 결혼 보다는 육아, 임신 및 출산의 비율이 높았다. 즉 맞벌이가구 비율이 점차 높아지고 있는 것은 사실이지만 40-50대 가구 는 출산으로 인해 경력단절을 경험한 후 육아를 마치고 다시
취업을 하고 있는데 비해서, 젊은 세대들은 아직 출산이나 육아로 인해 맞벌이가구의 비율이 상대적으로 낮음을 알 수 있다.

현재 여성가족부는 가족친화제도를 확산시키기 위해 다 양한 정책을 펴고 있으며 특히 가족친화컨설팅과 가족친화 직장환경 조성사업, 가족친화지수 조사 및 공표 등의 다양한 사업을 실시하고 있다. 그러나 앞으로 계속 증가하는 맞벌이 가정과 그 가족의 일-가정 균형요구에 부응하고 여성의 취업 을 증진시키기 위해서는 기초적인 제도를 넘어 다양한 제도 를 제시해야 할 것이다. 또한 새로운 정부의 출범과 함께 새 로운 가족정책을 그려보는 것은 의미가 있을 것이다.

지금까지 일-가정 양립 혹은 일-가정 균형에 관한 많은 연 구들이 있었다. 크게 양분하자면 정책수립에 관한 연구와 일 -가정 균형실태에 관한 연구들이 있었고, 정책분야에서는 일 -가정 양립지원을 위해 장기적이고 광범위한 가족정책을 구 성하기 위한 세부영역연구들이 있었다(Jeong, 2011). 이에 비해서 본 연구는 일-가정 양립지원정책의 큰 틀과 실제 시 행 사업을 기초로 정책을 구체화시킬 수 있는 방안을 강구하 고자 한다.

따라서 본 연구는 일-가정 양립지원제도의 시행중에 나타 난 문제점들을 근거로 일-가정 양립지원을 위한 정책대안을 제시함으로써 좀 더 실효성이 있는 제도 마련에 도움이 되도 록 하는데 목적이 있다. 이를 위하여 우선 건강가정기본계획 에서 차지하는 일-가정 양립정책의 비중을 분석한다. 세부적 으로는 일-가정 균형을 방해하는 노동시간의 양과 융통성을 검토하고 육아관련 휴직휴가제 및 가족사랑의 날 실시 현황 을 파악한다1). 마지막으로 가족친화지원사업의 사업성과를 분석하고 성과제고 방안을 제시함으로써 일-가정 양립지원 정책의 대안으로 삼고 정책 사업 확대에 기여하도록 한다.

․ 일-가정 양립지원 정책 및 관련사업의 성과와 현실

\section{1. 넓은 범위의 일가정 양립지원 정책}

현재 일-가정 양립지원 정책은 제 2차 건강가정기본계획 중 가족친화적 사회환경조성 영역의 정책과제에 포함되어 있다. 일-가정 양립지원정책은 $\mathrm{OECD}$ 의 정의에 의하면 가족

1) 육아휴직은 일가정 균형의 주요 지표로써 우리나라의 일가 정 균형 수준을 가늠하기 위해 $\mathrm{OECD}$ 자료를 제시한 것이 며, 가족사랑의 날은 지난 2009년부터 가족친화 문화조성 의 일환으로 우리나라 정부가 자체적으로 시행하는 캠페인 으로써 그 현황 조사를 위해 일차적으로 가족친화 직장문화 를 실천하고 있다고 판단할 수 있는 가족친화인증을 받은 기업(관)(2008 ) 대상으로 추진 현황을 검토한 것으로 분석 대상이 상이함을 밝힌다. 
친화정책으로 명기되어 근로자의 가족자원을 지원하고 아동 발달에 적절한 환경을 조성함으로써 근로자들이 일과 돌봄 을 양립하여 생활할 수 있게 해주며, 양성평등한 고용정책을 촉진시키는 제반정책을 포함한다. 최근의 변화는 가족친화정 책은 근로자의 가족을 중요하게 수용한다는 입장에서 맞벌 이 가족이 증가함에 따라 일하는 부모에 대한 적극적 지원정 책의 의미로 근로자의 일과 가정의 양립을 지원하는 일-가정 양립(Work-Family Balance) 혹은 일-생활균형(Work-Life Balance) 정책과 상통하는 개념으로 확장되고 있다(Hong et al., 2011). 또한 제 2차 건강가정기본계획에서 제시된 가족 친화적 사회환경조성 영역은 크게 가족친화적인 직장환경조 성과 가족친화적인 지역환경조성으로 구분된다. 2006년부터 구체화된 정책으로 시작된 일-가정 양립지원정책의 내용과 비중의 변화를 알아보기 위하여 <Table 1>에서 제 1 차 건강 가정기본계획과 제 2 차 건강가정기본계획에 포함된 일-가정 양립정책부분을 비교하였다.

1 차 계획에서는 직장-가정의 양립 영역과 가족친화적 사 회환경의 조성 영역 등 2 개 영역으로 구분되어 전체 6 개 영 역 중 2 개를 차지하였다. 이에 비해 2 차 계획에서는 가족친 화적인 사회환경조성 영역으로 일원화되어 전체 5 개 영역 중 1 개를 차지하였다. 2 차 계획에서는 남성의 가족생활부분 을 따로 분리하기는 하였지만 전체 11 개 대과제 중 3 개가 할
애되었다. 영역의 구분이나 대과제의 수를 기준으로 단편적 으로 비교하기에는 다소 무리가 있을 것이고 과제수를 조정 하기 위한 제한이 있었겠지만, 가장 표면적으로 드러나는 양 적인 비교만을 기준으로 본다면 1 차 계획의 14 개 대과제 중 5 개를 차지했던 것에 비해 2차 계획에서는 영역확보나 대과 제의 수에서 비중이 줄어들었다고 볼 수 있다.

2 차 건강가정기본계획 중 가족친화적인 사회환경 조성은 가족친화적인 직장환경 조성과 가족친화적인 지역환경 조성 으로 구성되어 있으며 각각의 세부 과제는 다음과 같다.

4. 가족친화적인 사회환경 조성

4-1. 가족친화적인 직장환경 조성

1) 육아를 위한 휴가, 휴직제도의 실효성 제고

2) 유연근무형태 확산

3) 가족친화기업 및 직장보육시설 확대

4-2. 가족친화적인 지역환경 조성

1) 가족친화 지역 인프라 구축

-가족친화적 지역환경 조성을 위한 기반 확보

-지역의 가족안전성 강화-아동, 청소년 유해환경 개선 -청소년 성보호 강화

2)가정폭력 예방 및 가족구성원 인권보호

Table 1. Comparison of Work-Family Balance Policy in 1st \& 2nd Plan for Healthy Family

\begin{tabular}{|c|c|}
\hline 1st Plan for Healthy Family(2006-2010) & 2nd Plan for Healthy Family(2011-2015) \\
\hline $\begin{array}{l}\text { 1. Socialization of Family Care } \\
\text { 1-1. Decrease of Burden for Family Care } \\
\text { 1-2. Social Support to Family Care }\end{array}$ & $\begin{array}{l}\text { 1. Enlarging of Family Value } \\
\text { 1-1. Spread of Healthy Family Culture } \\
\text { 1-2. Support for Father's Involvement to Family Life }\end{array}$ \\
\hline $\begin{array}{l}\text { 2. Work-Family Balance } \\
\text { 2-1. Support for Men's Involvement to Family Life } \\
\text { 2-2. Support for Women's Involvement to Labor Market }\end{array}$ & $\begin{array}{l}\text { 2. Reinforcement of Support to Family Care } \\
\text { 2-1. Various Support for Family Care } \\
\text { 2-1. Support to Parental Role }\end{array}$ \\
\hline $\begin{array}{l}\text { 3. Support to Various Family } \\
\text { 3-1. Organizing of the Comprehensive Support System for Single } \\
\text { Family } \\
\text { 3-2. Support to Social Integration of Multi-Cultural Family } \\
\text { 3-3. Customized Service to Dysfunctional Family }\end{array}$ & $\begin{array}{l}\text { 3. Empowerment for Various Family } \\
\text { 3-1. Enlarging of Support \& Customized Service for Single } \\
\text { Family } \\
\text { 3-2. Enlarging of Support for Multi-Cultural Family } \\
\text { 3-3. Construction of Support System for Family Caregiver \& } \\
\text { Dysfunctional Family }\end{array}$ \\
\hline $\begin{array}{l}\text { 4. Construction of Family-Friendly Social Environment } \\
\text { 4-1. Family-Friendly Workplace } \\
\text { 4-2. Family-Friendly Community } \\
\text { 4-3. Safe Family Living Environment }\end{array}$ & $\begin{array}{l}\text { 4. Construction of Family-Friendly Social Environment } \\
\text { 4-1. Family-Friendly Workplace } \\
\text { 4-2. Family-Friendly Community }\end{array}$ \\
\hline $\begin{array}{l}\text { 5. Creation of New Family Relation \& Culture } \\
\text { 5-1. Improvement of Family Relation \& Prevention of Family } \\
\text { Problem } \\
\text { 5-2. Creation of Healthy Family Culture }\end{array}$ & $\begin{array}{l}\text { 5. Reinforcing of Infrastructure for Implementing Family Policy } \\
\text { 5-1. Reinforcing of Supporting System \& Effectiveness in Family } \\
\text { Policy } \\
\text { 5-2. Specialization \& Differenciation of Family Service System }\end{array}$ \\
\hline
\end{tabular}

6. Enlarging of Infrastructure for Implementing Family Policy

6-1. Setting of Overall System

6-2. Enlarging \& Supplement of Infrastructure 
하지만 주제의 성격상 가족친화적인 지역환경 조성 부분 이 실질적으로 가족친화정책이기 보다는 안전한 환경에 치 중되어 있음을 알 수 있다. 11 개 대과제 중 하나인 가족친화 적인 지역환경 조성은 가족친화 지역 인프라 구축과 가정폭 력 예방 및 가족구성원 인권보호로 구분되어 직접적으로 일가정 양립을 위한 지역환경이라고 보기는 어렵다. 또한 지역 인프라 구축부분도 지역환경 조성을 위한 기반 확보 외의 세 가지 소과제는 안전과 성보호에 할애함으로써 일-가정의 균 형이라는 목표에서 도입된 '가족친화'의 의미는 없는 것으로 볼 수 있다. 물론 가족친화의 개념을 광의적으로 해석하여 가족친화적인 지역사회의 개념을 넓게 해석할 수 있으나 이 는 일-가정 균형을 목표로 하거나 확대 개념 하에서의 광범 위한 정책이지 안전 개념 위주의 가족친화지역은 아닐 것이 다. 따라서 일-가정 양립의 문제를 해결하면서 추가로 안전 의 문제가 포함되는 것이 바람직하다고 판단되며, 가족친화 라는 명칭 하에서 서로 다른 많은 내용이 들어가 상대적으로 일-가정 양립의 중요성이 축소되는 정책편성이 되어서는 안 될 것이다.

뿐만 아니라 일-가정 양립지원정책의 대표적인 두 축이 가족친화기업과 가족친화지역으로서의 가족친화마을 조성 으로 현재 여성가족부의 정책에서는 가족친화마을과 여성친 화마을이 양립하여 정책이 분산되고 있다. 다만 가족친화지 역 관련 논의는 이번 주제인 가족친화기업 관련 내용을 벗어 나 있어 향후 다루어질 논점으로 삼고자 한다.
2. 노동관계법 시행 상 나타난 일-가정 양립 실태

1) 노동시간의 양과 융통성

어느 나라보다도 긴 우리나라 노동자들의 노동시간을 줄 이기 위하여 정부는 2003년 8월 주 40시간 노동을 의무화하 고 경과조치로 기업규모별로 연차적으로 적용하여 2012년 1월 까지 완료하였다. 2004년에 1,000인 이상 기업과 금융보험업 및 공기업을 시작으로 하여 2011년 20인 미만 사업장에 주 40 시간제를 적용하여 점차적으로 노동시간을 줄여가고자 하 였다.

그 결과, 과거에 비해 노동시간이 많이 감소하기는 하였으 나 여전히 연간노동시간이 $\mathrm{OECD}$ 의 평균 노동시간인 1,749 시간보다 훨씬 긴 2,193시간으로 나타났다(OECD, 2012). 주 당근무시간이 주 45 시간 이상인 사람의 비율이 전체 $60.2 \%$ 로 조사되었고, 남성의 경우에는 $64.7 \%$ 였다. 종사상 지위별 로 보면, <Table 2>, <Table 3>에서와 같이 임금노동자보다 자영업자들의 노동시간이 길었으며 직업별로는 서비스종사 자와 기능원 등의 노동시간이 길었다(Korea Occupational Safety and Health Agency, 2011).

이렇게 아직도 장시간 근로를 하고 있음에도 불구하고 주 40 시간 근무제 도입 시기를 조사한 연구에서는 이 제도의 도 입을 고려하지 않은 경우가 $10 \%$ 정도이며 기업규모가 적을 수록 도입을 고려하지 않는 것으로 나타났다(<Table 4>참 고). 이런 현상으로 인해 근로시간이 1 년새 오히려 증가하였 고 대기업은 줄었으나 중소기업은 늘어난 것으로 나타나고 있다(E-daily, 2012). 또 산업별로 장시간 근로가 심각한 수준

\begin{tabular}{llccc}
\hline & total & regular employees & temporary employees & daily workers \\
\hline \hline 1985 & 51.4 & 48.1 & 68.3 & 43.4 \\
1990 & 56.2 & 53.3 & 68.7 & 44.2 \\
1995 & 49.3 & 47.9 & 56.8 & 40.1 \\
2000 & 43.7 & 44.1 & 50.5 & 29.3 \\
2005 & 51.4 & 51.6 & 57.2 & 37.3 \\
2006 & 50.6 & 50.4 & 56.5 & 38.0 \\
2007 & 47.2 & 46.3 & 53.5 & 35.7 \\
2008 & 43.5 & 42.2 & 50.1 & 33.1 \\
2009 & 43.0 & 43.5 & 46.7 & 30.8 \\
2010 & 41.5 & 42.2 & 44.1 & 29.7 \\
2011 & 38.3 & 39.6 & 39.5 & 27.7 \\
\hline
\end{tabular}

Source: Statistics Korea(2012). e-Country Index(http://www.index.go.kr/egams/index.jsp). 


\begin{tabular}{|c|c|c|c|c|c|c|c|c|c|c|c|}
\hline & & \multicolumn{5}{|c|}{2010} & \multicolumn{5}{|c|}{2011} \\
\hline & & $\begin{array}{l}\text { employees } \\
(\mathrm{N})\end{array}$ & $\begin{array}{l}\text { less } \\
\text { than } \\
35 \mathrm{~h}\end{array}$ & $35 \sim 45 h$ & over $45 \mathrm{~h}$ & $\mathrm{n} / \mathrm{r}$ & $\begin{array}{l}\text { employees } \\
\text { (N) }\end{array}$ & $\begin{array}{l}\text { less } \\
\text { than } \\
35 \mathrm{~h}\end{array}$ & $\begin{array}{l}35 \sim \\
45 h\end{array}$ & $\begin{array}{c}\text { over } \\
45 \mathrm{~h}\end{array}$ & $\mathrm{n} / \mathrm{r}$ \\
\hline Total & sub-total & 10,019 & 13.3 & 32.7 & 54.0 & - & 50,032 & 9.0 & 30.7 & 60.2 & 0.0 \\
\hline \multirow{2}{*}{ sex } & male & 5,850 & 8.9 & 32.7 & 58.4 & - & 29,138 & 5.6 & 29.7 & 64.7 & 0.0 \\
\hline & female & 4,169 & 19.5 & 32.6 & 47.9 & - & 20,894 & 13.8 & 32.2 & 54.0 & 0.0 \\
\hline \multirow{5}{*}{$\begin{array}{l}\text { engagement } \\
\text { status }\end{array}$} & self-employed & 1,746 & 16.3 & 14.5 & 69.3 & - & 8,616 & 11.4 & 13.6 & 75.0 & 0.0 \\
\hline & $\begin{array}{l}\text { self-employed } \\
\text { with employee }\end{array}$ & 622 & 4.9 & 23.7 & 71.4 & - & 3,098 & 2.6 & 18.6 & 78.8 & 0.0 \\
\hline & wage earner & 7,114 & 12.8 & 39.3 & 47.9 & - & 34,788 & 8.1 & 37.2 & 54.8 & 0.0 \\
\hline & unpaid family worker & 536 & 20.6 & 14.1 & 65.2 & - & 2,562 & 16.4 & 15.1 & 68.5 & 0.0 \\
\hline & other & - & - & - & - & - & 968 & 24.1 & 31.7 & 44.2 & 0.0 \\
\hline \multirow{10}{*}{ occupation } & manager & 382 & 3.3 & 46.5 & 50.2 & - & 995 & 2.6 & 42.8 & 54.6 & 0.0 \\
\hline & professional & 1,764 & 12.7 & 43.5 & 43.8 & - & 8,368 & 9.0 & 43.1 & 47.9 & 0.0 \\
\hline & clerk & 1,436 & 4.7 & 60.3 & 35.0 & - & 8,550 & 2.3 & 55.4 & 42.3 & 0.0 \\
\hline & service worker & 977 & 19.6 & 16.8 & 63.5 & - & 5,124 & 10.3 & 14.8 & 74.8 & 0.0 \\
\hline & sales worker & 1,379 & 10.4 & 21.2 & 68.4 & - & 7,396 & 6.3 & 18.6 & 75.2 & 0.0 \\
\hline & $\begin{array}{c}\text { skilled agr./for./fishery } \\
\text { worker }\end{array}$ & 698 & 27.6 & 20.8 & 51.6 & - & 3,502 & 23.9 & 23.1 & 53.0 & 0.0 \\
\hline & $\begin{array}{c}\text { craft/related trade } \\
\text { worker }\end{array}$ & 952 & 6.7 & 25.1 & 68.2 & - & 4,791 & 5.2 & 18.4 & 76.3 & 0.0 \\
\hline & $\begin{array}{l}\text { plant and machine } \\
\text { ope./assembler }\end{array}$ & 971 & 5.1 & 28.2 & 66.6 & - & 5,332 & 3.2 & 23.7 & 73.1 & 0.0 \\
\hline & elementary occupations & 1,421 & 27.2 & 23.7 & 49.1 & - & 5,883 & 22.1 & 24.8 & 53.2 & 0.0 \\
\hline & soldier & 39 & 0.0 & 28.3 & 71.7 & - & 90 & 0.0 & 65.2 & 34.8 & 0.0 \\
\hline
\end{tabular}

Source: Korea Occupational Safety and Health Agency(2011). The disaster statistics analysis of occupational safety \& health research institute.

Table 4. Introducing time of Standard Working Week of 40 Hours

(unit: \%)

\begin{tabular}{|c|c|c|c|c|c|c|c|}
\hline & & before 2011.7.1 & from 2011.7.1 & 2011.8-12 & after 2012.1.1 & out of consideration & total \\
\hline \multicolumn{2}{|c|}{ total } & 33.0 & 41.4 & 7.0 & 8.4 & 10.2 & 100.0 \\
\hline \multirow{3}{*}{$\begin{array}{c}\text { \# of } \\
\text { employees }\end{array}$} & $5-9$ & 29.9 & 32.9 & 9.0 & 11.4 & 16.8 & 100.0 \\
\hline & $10-14$ & 21.8 & 55.6 & 6.0 & 9.8 & 6.8 & 100.0 \\
\hline & $15-19$ & 47.1 & 37.9 & 5.7 & 3.6 & 5.7 & 100.0 \\
\hline \multirow{2}{*}{ industry } & manuf. & 31.0 & 44.6 & 6.6 & 7.8 & 10.0 & 100.0 \\
\hline & service & 41.8 & 22.6 & 8.8 & 11.4 & 11.4 & 100.0 \\
\hline
\end{tabular}

Source: Yang(2011). The implementing actual condition and implication of small scale company's weekly forty-hour system. e-KIET Information of Industrial Economy No.523.

으로 조사되어 정부의 단시간 근로정책과 배치되는 현상이곳곳에서 나타나고 있다(Seoul Newspaper, 2012). 
Table 5. Workers taken Maternity \& Parental Leave Benefits

(unit: person, million won)

\begin{tabular}{|c|c|c|c|c|c|c|c|c|c|c|}
\hline & & 2003 & 2004 & 2005 & 2006 & 2007 & 2008 & 2009 & 2010 & 2011 \\
\hline \multicolumn{2}{|c|}{ maternity leave } & 32,133 & 38,541 & 41,104 & 48,972 & 58,368 & 68,526 & 70,560 & 75,742 & 90,290 \\
\hline \multicolumn{2}{|c|}{ (amount of benefit) } & 33,522 & 41,610 & 46,041 & 90,886 & 132,412 & 166,631 & 178,477 & 192,564 & 232,915 \\
\hline \multirow{3}{*}{$\begin{array}{l}\text { parental } \\
\text { leave }\end{array}$} & total & 6,816 & 9,304 & 10,700 & 13,670 & 21,185 & 29,145 & 35,400 & 41,733 & 58,137 \\
\hline & female & 6,712 & 9,123 & 10,492 & 13,440 & 20,875 & 28,790 & 34,898 & 40,914 & 56,735 \\
\hline & male & 104 & 181 & 208 & 230 & 310 & 355 & 502 & 819 & 1,402 \\
\hline \multirow{3}{*}{$\begin{array}{c}\text { (amount of } \\
\text { benefit) }\end{array}$} & total & 10,576 & 20,803 & 28,242 & 34,521 & 60,989 & 98,431 & 139,724 & 178,121 & 276,261 \\
\hline & female & 10,415 & 20,477 & 27,755 & 33,989 & 60,249 & 97,449 & 138,221 & 175,582 & 270,500 \\
\hline & male & 161 & 326 & 487 & 532 & 740 & 982 & 1,503 & 2,539 & 5,761 \\
\hline
\end{tabular}

Source: Statistics Korea(2012). e-Country Index(http://www.index.go.kr/egams/index.jsp).

이런 상황이므로 정부에서 심혈을 기울이는 유연근무제 시 행도 실시비율이 높지 않다. 고용노동부의 조사(Ministry of E. \& L., 2011)에 의하면, 탄력적 근로시간제 도입기업의 비 율은 $6.1 \%$, 선택적근로시간제 도입비율은 $3.3 \%$, 재량근로시 간제 도입비율은 $4.1 \%$ 로 저조하였다(Pyeon, 2012).

또한 지역별고용조사 결과에 의하면(Statistics Korea, 2012), 2012년 3월 기준 전체 임금근로자 중 유연근무제를 활용하는 임금근로자는 $13.4 \%$ 로 나타났다. 성별로 보면 남 자는 $9.5 \%$, 여자는 $18.6 \%$ 가 유연근무제를 활용하는 것으로 나타났다. 또 임금근로자의 세부유형별로 보면, 시간제근로 제는 $59.6 \%$, 출퇴근시간자율제는 $17.2 \%$, 선택적 근로시간제 는 $9.2 \%$ 를 활용하는 것으로 나타났다.

종사상지위별로 임금근로자의 유연근무제 활용비율을 살 펴보면, 상용근로자 중 유연근무제를 활용하는 비율은 $6.7 \%$, 임시 · 일용근로자는 $28.3 \%$ 로 상용근로자가 $21.6 \%$ 만큼 낮게 나타났고, 임시 · 일용근로자의 유연근무제 활용비율이 높게 나타난 것은 유연근무제 유형 중 시간제근로제를 임시 - 일용 근로자가 많이 활용하였기 때문으로 보인다. 유연근무제를 활용하는 임금근로자의 직업별 비중을 살펴보면, 서비스- 판 매종사자와 관리자 - 전문가 및 관련종사자는 각각 $26.6 \%$, $26.1 \%$ 로 큰 비중을 차지하였고, 농림어업숙련종사자와 기 능 - 기계조작 - 조립종사자는 각각 $0.2 \%, 8.8 \%$ 로 낮은 비중 을 차지하였다.

\section{2) 육아관련 휴직휴가제}

연도별 출산 및 육아휴직 현황을 보면, 2011년 기준 여성 근로자 육아휴직자수는 56,137명이었고 남성 육아휴직자수 는 1,402 명이었다. <Table 5>에 의하면, 연도별 증가율로 볼 때 남성 육아휴직자의 수가 여성 육아휴직자수보다 빨리 증 가하고는 있지만 여전히 절대적인 수가 적은 것이 사실이다. 특히 육아휴직사용자 약 58,000 여 명 중 공무원이 차지하는
비율이 약 $58 \%$ 이며 남성 육아휴직자 중 공무원의 비율은 $85 \%$ 로서 $\mathrm{OECD}$ 회원국 중 최하위를 차지하고 있다.

3) 가족친화문화

가족친화제도 중 일-가정 양립 문화를 확대하기 위한 관 련제도로 가장 대표적인 것이 가족사랑의 날이다. 매주 수요 일 정시퇴근을 권장함으로써 가정과 일의 행복 밸런스를 맞 추고자 시작된 가족사랑의 날은 직장과 가정 양쪽에서 시너 지효과를 얻을 수 있는 가족사랑 실천운동으로서 건강가정 기본법 제 28조(가정생활문화의 발전)에 법적 근거를 두고 있으며 기업과 학교, 언론 등의 동참으로 2009년 10월 셋째 수요일을 첫 번째 지정일로 하여 시작되었다.

가족친화인증사업(2008 )과 가족친화포럼2)(2011 )이 진 행되면서 참여기업들의 가족사랑의 날 시행률은 많이 높아 졌다. 가족친화인증기업 157곳을 대상으로 '가족사랑의 날' 시행여부를 조사(Family Friendly Support Center, 2012) 하여 155 곳으로부터 응답받은 결과, 이 중 $80.0 \%$ 인 124 기업 이 가족사랑의 날을 시행하고 있었다. 공공기관이 $92.3 \%$ 로 시행률이 가장 높았고 중소기업이 $77.6 \%$, 대기업이 $63.4 \%$ 로 나타났다. 가족사랑의 날 시행주기는 매주 1회 시행이 $68.1 \%$ 로 가장 많았고, 월 1 회가 $16.4 \%$, 기타 $15.5 \%$ 였다. 또한 '규 정화하여 운영하지 않고 가족사랑의 날을 운영하고 있다'고 응답(8곳, $6.5 \%)$ 한 곳도 있어 '가족사랑의 날'은 규정화하지 않아도 점차 하나의 조직문화로 정착되어가는 것을 알 수 있 다. 앞으로는 가족사랑의 날 캠페인이 정시퇴근에만 그치지 않고 가족과 함께 적극적으로 시간을 활용할 수 있는 문화로 정착될 필요가 있다.

가족사랑의 날 참여도에 대해서도 매우 높다고 응답한 기

2) 일과 가정을 조화롭게 병행할 수 있는 직장환경 조성을 위 해 가족친화인증기업 - 기관, 관련 전문가가 상호교류와 협력 을 목적으로 2011년 3월에 창립한 자발적 협의체 
업이 $43 \%$ 로 나타났고, 높음과 보통이 $29 \%$ 와 $23.7 \%$ 로 나타 나 인증기업의 참여도는 대체로 만족할만하다고 할 수 있다. 또한 제도시행으로 인해 직원만족도가 높아져서 생산성이 증대될 것이라고 응답한 비율이 $32 \%$ 로 가장 많았고 눈치 보 지 않고 정시퇴근이 가능한 분위기가 형성된다고 응답한 비 율이 $28 \%$ 로 나타나 전체적인 만족도나 문화형성에 긍정적 인 영향을 미친다고 볼 수 있다.

그러나 전체 기업을 대상으로 하면 가족사랑의 날 시행정 도가 현저하게 떨어짐을 알 수 있다. 가족친화지수조사(Family Friendly Support Center, 2011)에 의하면 가족친화 문화를 조성하기 위한 지원제도 중 정시퇴근을 의무화하는 '가족의 날' 활용도는 $38.6 \%$ 로 나타났다. 기업유형별로 공공 부문은 $45.4 \%$ 로 국가 행정기관이나 공공기관 등의 지원으로 다소 높았지만 상장법인은 $29.3 \%$ 로 낮았다. 특히 업종별로 건설업이나 100 인 미만의 사업장은 $20 \%$ 를 밑돌아 시행률이 매우 낮았다. 그렇다면 소득수준이 높지 않은 맞벌이가정의 근로자들이나 취업주부들이 대부분 속해있는 일반기업, 그 중에서도 소규모기업의 시행률은 더욱 낮을 것으로 보인다.

\section{3. 가족친화지원사업 주요 사업성과 \\ 1) 컨설팅사업}

가족친화컨설팅의 사업 내용을 파악하고 향후 개선점을 찾기 위해 2007년 여성가족부, 2008년 보건복지가족부의 가 족친화경영컨설팅 결과보고서를 참조하였다. 이후 가족친화 컨설팅이 중단된 해를 제외한 2011년, 2012년의 가족친화컨 설팅 분석3)은 가족친화지원센터의 사업결과보고서 분석을 통해 이루어졌다.

기업이나 기관 등의 가족친화적인 문화 확산을 위해 실시 되는 가족친화컨설팅 지원사업은 기업이나 기관의 상황에 맞는 가족친화제도를 소개하고 도입을 지원하며 가족친화인 증의 참여도를 높이는데 도움이 된다. 기업의 입장에서 '가 족친화경영' 도입을 비용으로 인식하는 현실에서 경제적 여 건이 좋은 대기업 위주로 정착될 가능성이 높기 때문에, 중 소기업의 비용부담을 최소화하고 가족친화경영에 대한 인식 제고와 도입을 촉진하기 위해 가족친화컨설팅 지원은 중소 기업을 중심으로 지원되고 있다. 가족친화컨설팅 사업은 시 행초기 10 여개를 밑돌던 수치에서 가족친화지원센터가 생긴 2011년과 2012년에는 40여개의 컨설팅을 실시하며 정착단 계에 접어들었다고 할 수 있다(<Table 6> 참조). 지금까지 연도별 컨설팅 현황에 따르면 총 114 개 기업이 가족친화컨설 팅을 지원받았으며 이중 $42.1 \%$ 에 해당하는 48 개 기업이 가족

3) 한국건강가정진흥원 가족친화지원센터의 2011, 2012 가족친 화프로그램 컨설팅 및 직장교육 사업 결과보고서(내부자료).
친화인증을 받았다.

가족친화컨설팅은 여성가족부에서 2007년도부터 시작되 었으나 본격적인 틀이 갖춰진 것은 2011년 여성가족부가 한 국건강가정진흥원을 가족친화지원센터로 지정하면서부터라 고 볼 수 있다. 가족정책 업무가 여성부와 보건복지부간 이 관과정을 몇 차례 거치면서 가족친화컨설팅 업무 역시 다양 한 기관에서 수행됨에 따라 일관성있는 사업확대가 이루어 지지 못하였으며 2009년과 2010년에는 가족친화컨설팅 업 무 자체가 중단되었다. 그러다가 가족정책 업무가 다시 여성 가족부로 이관된 이후 한국건강가정진흥원이 가족친화지원 센터를 지정받으면서 다시 체계를 갖춰 시행되고 있다. 가족 친화지원센터에서 실시한 이후에도 2011년의 경우 유연근무 제 컨설팅을 포함 자문형과 맞춤형으로 운영하다 2012년에 는 3회차 방문하는 맞춤형컨설팅 중심, 그리고 다시 2013년 에는 집단형과 자문형, 맞춤형으로 구분하여 운영하고 있다.

가족친화컨설팅은 무엇보다 가족정책이 정부 부처간 이 관을 반복하면서 일관된 체계를 가지고 수행되지 못하였다 는 데에 가장 큰 문제가 있다. 수행기관과 소관부처의 변동 에 따라 가족친화컨설팅의 직접적인 목적이 분명하지 않은 것으로 나타나고 있다. 즉, 컨설팅의 목적이 조직 내 다양한 친화제도 도입수준을 진단하고 가족친화경영 확산을 위한 방안도출이 목적이지만 구체적인 성과를 무엇으로 볼 것인 가의 문제가 남는다. 하나의 방안은 가족친화인증과 컨설팅 을 유기적으로 연동하여 컨설팅 목표를 구체화하는 것이 될 수 있을 것이다.

\section{2) 가족친화사업}

가족친화사업은 저출산/고령화 사회에서 근로자가 가정 생활과 직장생활을 조화롭게 병행할 수 있는 가족친화적인 사회환경을 조성하기 위해 정책적으로 시행하고 있으며 그 주요 사업으로 가족친화인증사업, 가족친화포럼 운영, 가족 친화지수조사 등이 있다. 가족친화인증사업은 가족친화인증 을 통해 가족친화제도를 모범적으로 운영하고 있는 기업 등 에 대하여 심사를 통해 인증을 부여하고 있다. 가족친화인증 사업은 지난 2008년에 시작하여 매년 시행중이다. <Table 7> 에 제시된 바와 같이, 2008년 11개소의 인증으로 시작된 사업 은 매년 증가하여, 2011년과 2012년에는 각각 95개와 116개 (유효기간 연장기업 11 개 포함)로 급증하였다. 이는 점차 일-가 정 양립의 중요성이 강조되고 여성가족부의 인증기업에 대한 적극적인 인센티브 발굴, 즉, 가족친화 우수기업 정부포상, 가족친화경영대상, 그 외 22개 기관 72 개 사업에 우대하는 등의 인센티브 확대로 인증기업의 수가 증가하였다.

또한 가족친화포럼은 가족친화인증을 받은 기업과 공공 기관이 가족친화 선도적인 조직으로 가족친화사업을 확대하 고 서로 정보를 교류하는 사업이다. 가족친화포럼은 2011년 
Table 6. Consulting Project to Family Friendly Workplace

(unit: $N$ )

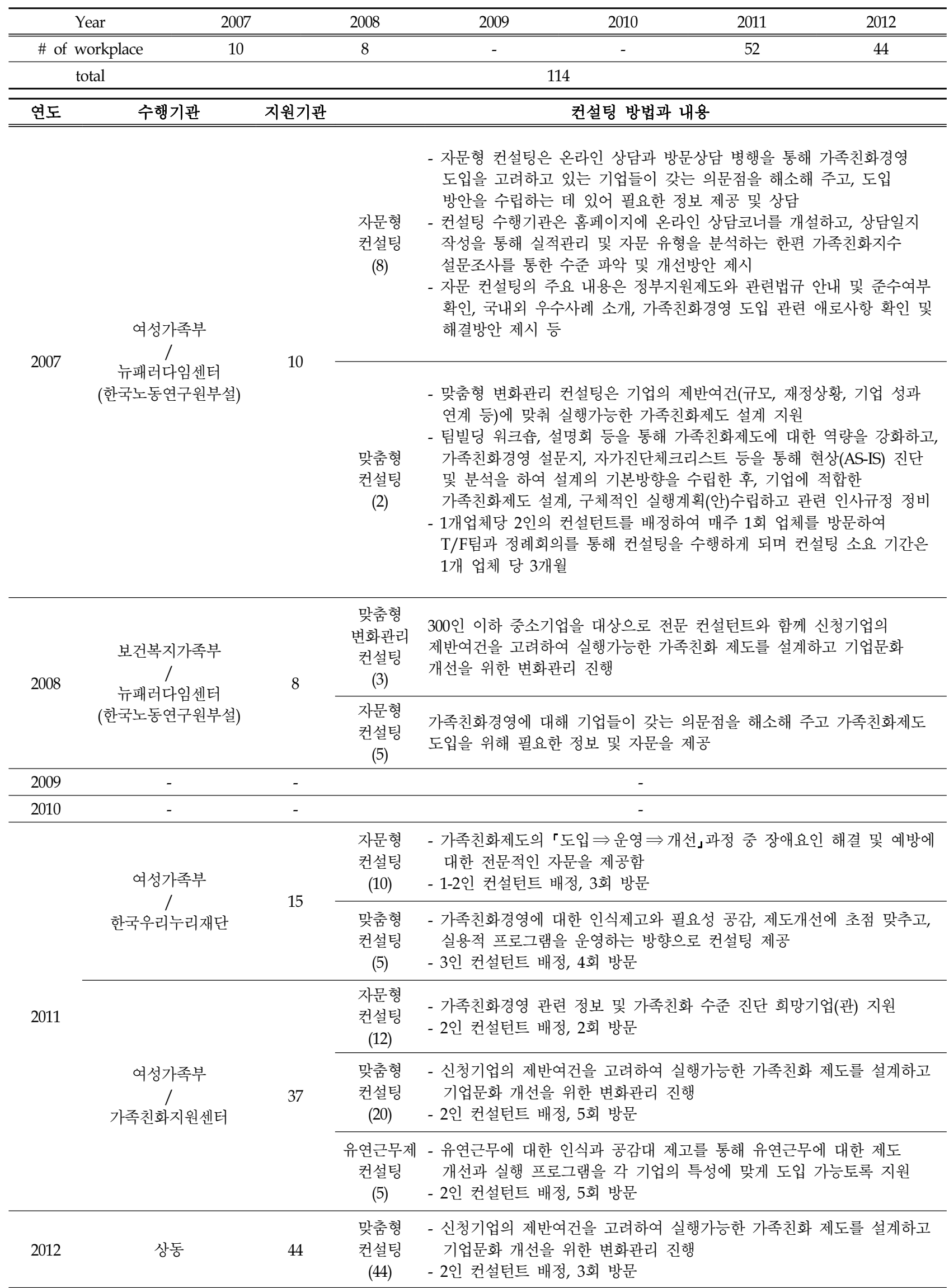


Table 7. Best Family Friendly Management Workplace of Korea

(unit: $N$ )

\begin{tabular}{ccccc}
\hline & Public Workplace & Large-size Workplace & Medium-Small Workplace & total \\
\hline \hline 2008 & 6 & 4 & 1 & 11 \\
\hline 2009 & 6 & 5 & 4 & 15 \\
\hline 2010 & 11 & 11 & 9 & 31 \\
\hline 2011 & 40 & 22 & 33 & 95 \\
\hline 2012 & 49 & 23 & 29 & 101 \\
\hline total & 112 & 65 & 76 & 253 \\
\hline
\end{tabular}

Ministry of Gender Equality and Family(2013). Information brochure of 2013 best family friendly management.

http://ffm.mogef.go.kr/business/reviewCompany.do.

3월 창립총회를 시작으로 현재까지 운영되고 있으며, 가족 친화경영이 기업경쟁력에 미치는 영향을 중심으로 특강과 사례발표 워크숍, 간담회 등을 실시한다.

한편 가족친화인증과 별도로 우리나라 전체 기업 및 공공 기관을 대상으로 가족친화정도를 평가하는 가족친화지수조 사도 실시되고 있는데, 이 사업에서는 가족친화제도의 운영 수준을 파악하고 이에 기초하여 가족친화적인 직장문화 조 성을 목표로 하고 있다.

이러한 가족친화사업은 앞서 언급한 비단 여성친화적인 직장환경 조성 및 여성의 경제활동참여율 증가에 따르는 대 응뿐 아니라 기업의 경쟁력을 높이고 모든 근로자의 삶의 질 을 향상하며 저출산에 따르는 국가적 위기의 최우선 대응전 략으로 추진하고 있다. 향후 가족친화적인 문화를 조성하기 위한 가족친화정책이 실효적인 성과를 거두기 위해서는 법 률적 규제보다는 직장영역에서의 자발적 변화를 지원하고 유도하는데 중점을 두어야 할 것이다.

\section{3) 피드백과 후속작업}

앞의 성과에서 제시했듯이 가족친화컨설팅 사업이나 가 족친화인증 사업 등에서 양적으로 많은 발전을 이룬 것을 볼 수 있다. 이 외에도 포럼을 통한 기업인적자원 교류, 교육전 문가의 양성이나 기업교육확대, 교육 매뉴얼 정리 등 많은 성과를 낸 것은 분명하다.

그러나 사업을 통해 수집되고 조사된 많은 자료들에 대한 후속작업이 뒤따르지 못하여 결과들을 충분히 활용하지 못 하고 있다. 예를 들어서, 컨설팅사업에서는 컨설팅결과와 제 안 제도들을 분석, 종합하여 다양한 기업형태별로 유형화하 는 후속 작업이 이루어져야 할 것이며, 또한 업종이나 형태, 규모 등에 따라 컨설팅의 방법이나 내용이 달라질 수 있으므 로 이에 따른 면밀한 분석 뒤 차후 컨설팅에 반영하는 작업 이 필요할 것이다.

가족친화인증이나 지수조사에서도 사업의 결과제시에 그 칠 뿐 충분한 활용이 이루어지지 않고 있다. 결과분석에 따
른 피드백 작업을 통해 사업의 개선과 성과의 확산이 가능할 것이지만, 아직은 인력이나 예산의 부족으로 인해 사업추진 에 머물러 있는 실정이다.

III. 정책대안과 사업 확대방안

\section{1. 일-가정 양립정책의 강화}

1) 다양한 형태의 유연근무제 확대실시

2010년 고용노동부의 유연근무제도 조사결과(Kim, 2010) 에 의하면 전체 사업체 중에서 단시간 근로제도를 도입한 사 업체는 $13.7 \%$, 보상휴가제는 $11.6 \%$, 선택적 근로시간제는 $6.1 \%$, 탄력적 근로시간제는 $7.3 \%$ 등으로 나타났다. 이 수치 는 재택근무제나 원격근무제 등에 비해서는 비율이 다소 높 지만 전체적으로 낮은 수치이며, 그 원인으로는 직무 및 업 무특성상 불필요가 가장 많았다. 그러나 유연근무제 이용자 에 대한 조사(Hong, Lee, \& Kim, 2011)에서는 취업부모들 에게 유연근무제가 무엇보다도 자녀양육과 일-가정 양립에 도움을 주었다는 점에서 중요하게 평가하는 것으로 나타났 다. 특히 여성들에게는 매우 유용하게 이용되었으며 취업중 단의 위기에 유용한 대안으로 평가한다. 또한 취업부모들은 유연근무제를 이용하면서 가족생활에 분명한 긍정적 변화를 경험하고 있다고 하였다.

우리나라에서는 아직 이와 관련된 실태조사나 사례조사 가 많지는 않지만 미국의 SC존슨사나 릴리사 등에서 범기업 적으로 실시되는 다양한 형태의 유연근무제를 통해 만족도 의 증가가 증명되고 있다(Hein, 2005). AFLac이나 ARUP연 구소 등도 일반적인 유연근무제 외에 회사의 상황에 맞는 다 양한 근무제를 실시하여 생산성 증가나 이직률 감소는 물론 이고 고객의 만족까지 이끌어내는 것을 볼 때, 다양한 형태 의 유연근무제를 활용하는 것이 시급하다(Workplace Flexibility Case Study. Work and Family Researchers Net- 
work. http://workfamily.sas.upenn.edu/site/workfamily. sas.upenn.edu/files).

\section{2) 파파쿼터제의 강화}

모성보호 관련 3법4)의 발전 및 일부 개정된 남녀고용평등 과 일-가정 양립지원에 관한 법률 등으로 인해 우리나라의 출산휴가 및 육아휴직 관련 정책은 다른 정책에 비해 비교적 잘 정착된 부분이다. 유럽의 일부 국가에는 미치지 못하지만 산전후 휴가제도의 시행률이나 이용률, 휴직제도의 사용률 등이 특히 대기업이나 공기업의 경우에는 $100 \%$ 에 가까우며, 여성의 경우 활용률이 더 높다(Jeong, 2009).

특히 아버지 육아휴직 할당제는 부모휴가기간 중 일정기 간 이상을 특정 부모가 이용할 수 없도록 하는 방안으로서 스웨덴에서 가장 먼저 논의되었다. 1993년 노르웨이에서 최 초로 제도화되었고 스웨덴에서는 1995년, 덴마크와 아이슬 랜드에서는 1999년에 제도화되었다. 스웨덴에서는 자녀출생 시 480 일간의 육아휴직을 사용할 수 있으며 아버지가 반드 시 60 일간의 육아휴직을 사용하도록 의무화하고 있다.

또한 노르웨이에서는 4 주간의 육아휴가기간을 아버지에 게 부여한다. 이러한 4 주간의 기간은 어머니들에게 양도할 수 없으며, 만일 아버지들이 그 휴가기간을 사용하지 못하면 그 휴가는 사용할 수 없다. 이러한 규칙은 아버지들이 자녀 가 태어난 첫 1 년 동안 자녀를 돌보는데 실제적으로 참여할 수 있도록 권장하기 위해 1993년 4월 도입되었다. 1990년대 초에는 2 3\% 아버지들만 육아휴가를 사용하였으나 이 제도 가 도입되면서 4 주간의 휴가를 사용하는 아버지들의 숫자가 가파르게 증가하였다. 2001년에는 아버지할당제의 혜택을 받 을 수 있는 아버지들의 약 $85 \%$ 가 이 권리를 사용하였다(Hein, 2005).

아이슬랜드에서는 6개월간 균일적으로 제공되는 육아휴 가(월등히 여성이용이 더 많음) 방식에서 아버지만 사용할 수 있고 어머니로 전이되지 않는 아버지 할당제 모델로 변화 되어왔다. 현재 육아휴가의 기간은 9개월로, 어머니를 위한 3 개월, 아버지를 위한 3개월, 그리고 부모가 공유할 수 있는 또 다른 3 개월 등 3 부분으로 나누어져 있다. 이 기간 동안 임금의 $80 \%$ 를 보상한다. 이 제도는 여러 단계를 걸쳐 발전 하였는데, 현재 아이슬랜드 아버지들의 $13 \%$ 는 아버지에게 만 허용된 일수보다 실제로 더 많이 사용한 것으로 나타났다 (Hein, 2005).

그러나 앞에서도 제시되었듯이 우리나라 여성의 출산휴가 및 육아휴직의 활용률에 비해 남성의 경우에 훨씬 적은 수치 이다. 이를 위해 제 2 차 건강가정기본계획에서는 외국의 부

4) 근로기준법, 남녀고용평등과 일 - 가정 양립 지원에 관한 법률, 모성보호법
성 육아휴직제도에 대한 소개 및 활용률 제고를 위한 홍보 강화를 정책으로 제시하고는 있지만 강제화되지 않음으로써 그 효과가 미비하다. 그러므로 일가정 양립 환경 조성을 위 해 정부차원의 법적 제도 마련과 함께 이에 따른 기업의 법 적 제도의 실제 활용 및 기업의 상황에 맞는 자체 제도 운영 이 균형적으로 이루어져야 한다는 전제하에 정책과제를 검 토하였다. 따라서 일반적인 육아휴직제의 사용보다는 아버 지의 육아휴직을 강제화하는 방안으로 파파쿼터제가 정책대 안으로 채택되어야 한다. 이는 여성의 육아휴직률 제고와 병 행하여 진행되어야 한다는 점이 중요하다. 즉 육아휴직이 여 성에만 집중된 상황에서 육아부담 및 일가정 양립이 여성만 의 역할로 규정되는 것이 아니라 개별 가정의 구성원들이 공 통 관심사로 인지하여 상호 협력하여야 실효적인 성과를 거 둘 수 있기 때문이다.

\section{3) 다양한 가족관련 휴가제의 활용}

Harrington(2007)의 일-생활 분야 리더들에 대한 연구에 서, 미래의 일-생활 분야에 영향을 줄 중요한 트렌드가 무엇 인가를 질문한 결과, 세대간 다양성, 세계화의 도전, 고령화 직원의 증가, 스트레스의 증가, 다양성의 증가, 업무과중, 기 술발전 등의 순으로 응답하였다. 즉 노동시장이 다양한 연령 층으로 구성되며 베이비부머의 은퇴시기와 맞물리면서 다양 한 연령 코호트의 욕구에 반응해야 하는 문제, 다양한 문화 와 나라에 따라 다르게 조성되어야 하는 업무환경과 일-생활 의 문제, 스트레스 관리, 직원들이 언제 어디서나 더 오래 일 을 많이 하게 됨으로써 생기는 스트레스 관리 등이 앞으로 닥칠 커다란 변화이며 해결과제라고 하였다.

우리나라의 경우에도 현재 고령화의 진행으로 인해 돌봄 문제에서 노인이 차지하는 비중이 증가할 전망이다. 아직은 저출산문제로 인해 아이돌봄에 관심을 집중하고는 있지만 비정기적으로 발생하는 아이돌봄의 공백문제나 노인을 포함 한 기타 가족원의 돌봄문제를 해결하기 위한 제도지원이 필 요한 실정이다.

일본에서 가족돌봄 휴가는 1999년부터 “자녀양육 및 가족 돌봄 휴가법령(Child Care and Family Care Leave Act)" 하에 사용되어왔다. 가족간호휴가는 상해나 질환, 신체적 및 정신적 장애 등과 같은 질병으로 인해 지속적인 돌봄이 필요 한 배우자, 자녀, 부모, 또는 양부모 등을 돌보기 위한 목적으 로 사용될 수 있으며, 휴가기간은 최대 3달까지 제한적이며, 일반적으로는 각 가족원들을 위해서 한번만 사용할 수 있다. 네델란드의 간병휴가는 말기환자의 가족들을 돌보기 위해 1 개월에서 6 개월을 사용할 수 있는 휴가로써, 실업보장 시스 템을 통해 유급으로 지급된다.

스웨덴에서도 가까운 가족들을 돌보기 위해 사용하는 가 족돌봄휴가는 사회보장 법에서 보장하고 있는데, 이는 최대 
60 일의 휴가를 보장받는다. 만일 환자가 에이즈 바이러스 (HIV) 보균자인 경우에, 최대 보장하는 휴가 기간은 240일이 다. 미국은 1993년 가족휴가와 질병휴가법(Family and Medical Leave Act)에서 허용한 12주의 무급휴가를 특별한 가 족의 이유와 의료적인 이유가 있을 때 이용한다(Hein, 2005).

우리나라에서는 현재 법적으로 근로자의 가족 돌봄을 위 한 지원으로 가족돌봄휴직(남녀고동평등과 일가정 양립지원 에 관한 법률, 제22조의 2)을 사용할 수 있으나 단서 조항인 대체인력 채용이 불가능한 경우, 정상적인 사업 운영에 중대 한 지장을 초래하는 경우 등 휴직이 불가한 것으로 되어 있 으며, 아울러 평균임금 산정기간에서 제외되는 등 제약이 따 른다. 따라서 다양한 노동력의 활용 및 다양한 가정 문제의 대처를 위해 일-가정 양립정책의 대표적인 제도로 기업차원 에서 보다 실효적인 방안이 모색되어야 할 것이다.

\section{2. 가족친화지원센터를 통한 사업 확대}

1) 가족친화지원센터의 광역 단위 설치

현재 가족친화지원센터는 1 개가 설치되어 가족친화 관련 지원사업을 수행하고 있으나 사업의 원활한 지원과 확대를 위해 광역 단위로 가족친화지원센터를 설치하는 것이 필요 하다. 이는 단순히 양적확대의 의미에서 나아가 최근 일가정 양립은 여성뿐 아니라 남성을 포함하는 모든 근로자의 삶의 질 문제로 확대되어 기업의 인적자원관리 측면에서도 지속 가능성을 위한 절실한 과제로 부각되었기 때문이다. 이에 대 해 가족친화제도가 기업성과에 긍정적인 영향을 미치고 있
음을 입증하고 가족친화적인 직장환경이 되도록 안내하는 역할을 가족친화지원센터를 통해 확대해야 할 필요성이 있는 것이다.

실제 지역에서의 가족친화정책에 대한 수요는 증가하고 있는 실정이다. 또한 '가족친화 사회환경의 조성 촉진에 관한 법률(2007년 제정)'에 근거하여 일부 지자체에서도 가족친화 관련 조례를 제정(<Table 8> 참조)함에 따라 중앙정부와 관 련 업무를 연계하고 조정할 필요성을 느끼고 있다.

이러한 조례가 마련된 지자체는 독자적으로 가족친화정 책을 펼치고 있어 일부 사업의 경우 중앙정부와 중복 문제를 낳고 있다(<Table 9> 참조). 중앙정부와 지자체 정책은 일관 성을 지니고 추진되어야 참여 기업의 혼선을 줄일 수 있다. 나아가 최근 많은 기업에서 가족친화제도에 대한 관심을 표 현하고 있어 정책적으로 이를 적극적으로 확산하기 위해서 는 다양한 지역에서 동시다발적으로 가족친화컨설팅을 진행 하는 것이 필요하다. 따라서 컨설팅 기준이 일관되게 마련되 고 컨설팅의 성과가 인증으로 이어질 수 있도록 체계화하는 작업은 시급하다고 볼 수 있다. 즉 보다 효과적인 컨설팅 사 업확대를 위해 광역 가족친화지원센터를 지정하고 중앙의 가족친화지원센터와 유기적 연계를 맺도록 하는 방안이 마 련되어야 한다.

2) 컨설팅사업의 다각화

현재 가족친화컨설팅은 여성가족부가 가족친화지원센터 를 지정하여 센터를 통해 기업의 규모, 가족친화지수의 정도, 업종에 제한을 두지 않고 지원하고 있다. 앞서 언급한 것처

Table 8. Local Regulations of Family Friendly Services

\begin{tabular}{|c|c|c|c|c|c|}
\hline Year & 2009 & 2010 & 2011 & 2012 & 2013 \\
\hline $\begin{array}{c}\text { Local } \\
\text { Regulations }\end{array}$ & $\begin{array}{c}\text { Gyeonggi } \\
(10.30)\end{array}$ & $\begin{array}{l}\text { Daegu } \\
(4.30)\end{array}$ & - & $\begin{array}{c}\text { Seoul(5.22) } \\
\text { Jeju(6.11) } \\
\text { Gwangju(10.15) } \\
\text { Incheon(11.19) }\end{array}$ & Ulsan(6.5) \\
\hline
\end{tabular}

Table 9. Local Condition of Family Friendly Consulting and Certification

(unit: $N$ )

\begin{tabular}{|c|c|c|c|c|c|}
\hline Year & 2009 & 2010 & 2011 & 2012 & 2013 \\
\hline $\begin{array}{c}\text { Local } \\
\text { Consulting }\end{array}$ & & $\begin{array}{c}\text { Changwon } \\
\text { (10) }\end{array}$ & $\begin{array}{c}\text { Gyeonggi(41) } \\
\text { Seoul(100) } \\
\text { Changwon(10) }\end{array}$ & $\begin{array}{c}\text { Gyeonggi(41) } \\
\text { Seoul(200) } \\
\text { Changwon(10) }\end{array}$ & $\begin{array}{c}\text { Gyeonggi(45) } \\
\text { Busan(9) } \\
\text { Seoul(200) } \\
\text { Incheon(10) } \\
\text { Changwon(13) }\end{array}$ \\
\hline Local & \multicolumn{5}{|c|}{ Gyeonggi 'Great Work Place' (in local regulations) } \\
\hline Certification & & 10 & 30 & 31 & \\
\hline
\end{tabular}


럼 2011년에는 기업의 상황에 맞추어 자문형과 맞춤형으로 2회 5회로 나누어 진행되었으며, 2012년에는 모두 동일하게 3회로 진행되었다. 그러나 가족친화컨설팅은 컨설팅의 목적, 기업의 특성 등에 따라 다양하게 이루어지는 것이 바람직하다.

우선 가족친화컨설팅은 집단컨설팅과 개별컨설팅으로 분 류할 필요가 있다. 집단 컨설팅은 인사담당자 대상 집중 교 육의 형태로 진행되며 가족친화지수가 낮은 기업, 또는 가족 친화경영에 대한 인식이 낮은 기업, 그리고 가족친화인증에 관심이 있는 기업 대상으로 실시할 수 있다. 이렇게 실시할 경우 개별적으로 방문하여 컨설팅을 할 때에 비해 비용과 시 간 절감의 효과가 발생하며, 기업 입장에서는 가족친화에 대 한 인식이 낮은 상태에서 컨설팅에 대한 부담감을 감소시킬 수 있을 것이다.

이에 비해 개별컨설팅의 경우는 교육보다 자문의 형태로 기 업의 애로사항을 해결하거나 가족친화지수를 높일 수 있는 방안에 대한 설계에 보다 집중하여야 하며, 이를 위해 한국 형 기업의 특성, 업종별 특성에 대한 분석 자료와 데이터가 필요하다. 또한 컨설팅 이후에 컨설팅 결과에 대한 업종별 결과보고 및 세미나 등으로 전체기업 대상 전체기업 대상 홍 보를 통해 업종별, 기업 특성별 모범사례를 공유할 수 있다.

\section{3) 기업인증사업의 변화}

현재 여성가족부는 가족친화지원센터와 별도의 인증사무 국을 두어 가족친화기업 인증을 수행하고 있다. 지금까지 가 족친화인증을 통해 가족친화제도 점검 및 가족친화직장문화 시행 기반을 마련하였으나, 다양한 기업의 참여 및 민간기업 이 주축이 되는 사업이 이루어지지 못한 채 공공기관의 비율 이 높은 상태이며, 지역별 다양성도 부족한 실정이다.

현재 가족친화인증은 수도권 중심으로 이루어지는 경향이 있는데, 2008년 2012년까지 총 253개 인증기업의 지역별 현 황을 보면, 서울 및 경기지역이 152 개사 $(60 \%)$ 이며 부산, 경남 지역이 48 개사 $(19 \%)$ 로 수도권 지역과 부산, 경남지역을 합 하면 $80 \%$ 를 차지하고 있다. 이러한 상황을 볼 때 향후 인증 추진시 지역별 기업 참여를 확대해야 하며, 그러기 위해서는 지속적으로 지자체에서 제공할 인센티브를 발굴하여 전체적 인 가족친화인증의 인센티브를 확대해야 한다. 또한 가족친 화인증기업 비율을 지자체 평가에 포함시킨다면 지자체의 가족친화사업을 확대시키기에 유리하다. 즉 가족친화인증기 업을 다수 배출한 지자체를 시상하는 제도 마련을 통해 지자 체의 관심을 유도, 확대하는 방안이 요구된다.

가족친화인증기업의 확산을 위해 우선 예산과 전문가 확 대가 필요하다. 또한 앞서 언급한 바와 같이 가족친화인증기 업 확대는 가족친화컨설팅과 연결되어 있으며, 가족친화컨 설팅의 목표가 곧 가족친화인증기업의 확대와 연결되어야 한다. 따라서 가족친화컨설팅을 지원할 센터의 예산과 인력
의 확대가 필요하며 두 사업이 통합적으로 연계되어 실시되 어야 한다.

특히 지자체의 가족친화인증사업을 구체화시켜 본다면, 자치단체별로 지역가족친화지원센터를 지정하여 가족친화 업무를 전담케 함으로써 가족친화지수 인증을 받아야 할 대 상 기업과 기관을 확정하는 것도 고려할 만하다. 이렇게 할 경우 가족친화지수 조사에 응할 기업의 수가 확정되어 관리 가 용이해진다. 또한 등록된 기업의 가족친화인증 비율과 가 족친화지수 점수가 지자체 평가에 반영된다면 지자체에서 기업의 가족친화경영과 가족친화컨설팅 및 인증에 대한 관 심이 증가할 것이다. 나아가 지자체별로 가족친화경영 확대 와 공로 인정을 위한 시상도 추진할 수 있을 것이다.

4) EAP 마련 및 건강가정지원센터 내 담당자 배치

현재 EAP(Employee Assistance Program)의 경우 정부 차원에서는 근로복지공단의 근로자지원프로그램으로 근로 자복지넷을 통해 제공되고 있다. 근무자들의 직무만족이나 생산성에 부정적인 영향을 미치는 문제를 근로자 스스로 해 결하도록 도와주는 상담서비스로서, 직장, 개인, 가정문제 등 전반에 걸쳐 개별 및 집단, 온라인과 오프라인으로 상담해주 는 서비스이다. 가족친화지원센터는 이 프로그램을 도입하 여 전국의 건강가정지원센터를 통해 기업 내 $\mathrm{EAP}$ 를 지원하 는 사업을 실시하는 것이 추가적인 역할에 부합할 것이다.

가족친화지원센터와 건강가정지원센터는 여성가족부의 정책 전달체계로서 서로 유기적으로 연결되어 있으므로, 가 족친화지원센터는 전국에 퍼져있는 건강가정지원센터를 통 해 사업을 확대함으로써 상호 추진 중인 사업을 효과적으로 확대해 나갈 수 있을 것이다. 즉 건강가정지원센터를 통해 근로자 가족문제 상담 연계, 아버지교육 등 기업을 대상으로 한 가족생활관련 교육을 실시할 수 있다. 특히 은퇴 전 노후 가족생활준비 프로그램 등을 연계하거나 이러한 프로그램을 가족친화인증을 받은 기업 대상 인센티브로 제공하는 것이 가능할 것이다.

특히 규모가 작은 기업의 경우, 직원의 긴급한 가족위기 때 아이돌보미를 직원 가정에 파견하고 기업에서 아이돌보 미 사용금액을 지원할 수 있다면 이 또한 직원가족의 일-가 정양립을 지원하는 프로그램으로 정착 가능하다. 현재 일부 기업이 직원과 가족대상 가족활동프로그램을 건강가정지원 센터와 연계하여 성공리에 진행하고 있는 점으로 볼 때 가족 친화지원센터와 전국 건강가정지원센터와의 유기적 연계와 사업 공유가 바람직하다. 


\section{IV. 결론 및 제한점}

본 연구는 일-가정 양립지원제도를 시행하는 과정에서 여 전히 정착, 확대되지 않는 제도들의 현황을 통해 문제점을 제기하고, 가족친화지원사업의 활동성과와 문제를 제시하였 다. 또한 이러한 문제를 해결하기 위한 대안들을 제안함으로 써 보다 실효성 있는 제도 마련에 도움이 되고자 하였다. 일가정 양립을 위해서는 기업, 가정 및 지역사회가 유기적으로 연결되어 작용해야 하지만, 본 연구에서는 가정을 지원하는 기업의 역할에 한정하여 기업의 가족친화제도를 독려하는 정책대안을 제시하였다.

일-가정 양립을 위해 개별 기업에 따라 다양한 형태의 제 도들이 필요하겠지만 본 연구에서는 시급히 정착되어야 할 제도로서 다양한 유연근무제의 확대와 파파쿼터제를 비롯한 가족돌봄제도의 강화를 강조하였다. 법적 근거에 따라 출산 휴가나 육아휴직제는 많은 기업에서 도입하고 있으나 여성 에 비해 남성의 가족돌봄제도가 잘 정착되고 있지 않아 파파 쿼터제를 제안하였으며, 가족돌봄에서는 상시 돌봄을 위한 제도는 비교적 준비되어 있는데 비해서 부정기적이고 간헐 적으로 나타나는 가족돌봄에 대한 대처방안이 부족하다는 점에서 가족돌봄휴직제의 용이성이 필요하다. 또 일-가정 양 립을 위해서는 모성보호제도의 정착을 넘어서 시간활용의 유연성이 필수적이므로 근로자의 상황에 맞는 유연근무제의 정착이 시급하다.

이러한 제도를 기업에 확대하기 위해서는 가족친화지원 센터가 지역 단위로 설치되어 각 지역의 기업에 맞는 제도를 제안하고 교육하는 것이 필요하다. 이런 점에서 센터의 확대 설치와 사업다각화, 인증사업의 전국적인 관심 제고 등을 제 안하였다. 또한 가족친화지원센터의 사업을 전국적으로 지 원, 보완하기 위해 건강가정지원센터의 사업과 연계하는 방 안을 제안하였다. 즉 일가정 양립은 자발적인 직장 영역에서 의 변화를 이끌어내야 하는 과제를 가지고 있으므로 법적인 규제를 통해서 접근하는 것뿐 아니라 제도적 지원 및 협력을 이끌어내는 전략을 동시에 실행하는 것이 중요하다. 이에 따 라 기업의 협력을 이끌어내기 위한 적극적인 지원 제도실행 기구인 가족친화지원센터의 효과적 운영과 사업 확대 및 유 관기관과의 연계 확대가 적극적으로 이루어져야 한다.

현재 건강가정지원센터에서는 찾아가는 아버지교육이나 가족친화교육을 기업 대상으로 실시하고 있으므로 가족친화 지원센터의 가족친화교육과 연계하여 확대 실시한다면 인력 이나 비용 면에서 추가부담이 적을 것이며, 특히 지역 소재 기업에 대한 접근과 이해라는 측면에서도 지역차원의 지원 이 필요하므로 두 센터간의 협력은 시너지효과를 낼 수 있을 것이다. 또한 가족친화전문가의 양성이나 파견 등도 지역중
심으로 이루어지는 것이 바람직하다.

따라서 기업 차원의 근로자 대상 가족친화제도마련 뿐만 아니라, 앞으로는 지역사회 내 자원연계에도 관심을 기울이 는 가족친화적 지역사회 지원방안에 대한 논의도 함께 진행 하는 것이 필요하다.

\section{REFERENCES}

E-Daily(2012). 'Spread of weekly forty-hour system'is useless thing - rather the working hours expand. 2012. 8. 29.

Family Friendly Support Center(2012). The $2^{\text {nd }}$ workshop of family friendly forum, "The usage of smart work for working hours refinement.'

Government of the Republic of Korea(2011). The $2^{\text {nd }}$ plan for ageing society and population.

Harrington, B.(2007). The work-life evolution study. Boston College Center for Work \& Family.

Hein, C.(2005). Jeong, Y., Yoon, S., Jeong, J., Cho, S. \& Cha, S. trans.(2013). Reconciling work and family responsibilities. Seoul: Yangseowon.

Hong, S., Chang, H., Lee, T., Bae, H., \& Lee, H.(2011). The study on corporate performance for the spread of family friendly system. Ministry of Gender Equality and Family.

Hong, S., Lee, M., \& Kim, D.(2011). Flexible working arrangements and family life. Korean Women's Development Institute.

Jeong, Y.(2009). A study on the law and policies relating to work-family balance. Journal of Korean Family Resource Management Association, 13(2), 85-105.

Jeong, Y.(2011). A study on family-friendly culture of workplaces and policies. Journal of Korean Home Management Association, 29(6), 123-136.

Jeong, Y.(2011). The balance of work and family for the family friendly society. Seoul: Ins Publishing Group.

Kim, T.(2010). The inquiry and analysis study of the real condition by working type. Ministry of Employment and Labor.

Korea Occupational Safety and Health Agency(2011). The disaster statistics analysis of Occupational Safety \& Health Research Institute.

Lee, C.(2012). The creation of new family culture for a 
long-hour work refinement, Source Book in the Commemorative Panel Discussion for Family Month by Ministry of Gender Equality and Family, 37-45.

Ministry for Health, Welfare and Family Affairs(2008). The final report of family friendly management consulting.

Ministry of Employment and Labor(2011). Additional survey of corporate labor cost.

Ministry of Gender Equality and Family(2007). The final report of family friendly management consulting.

Ministry of Gender Equality and Family(2011). 2011 family friendliness index survey report of corporation and public institution.

Ministry of Gender Equality and Family(2012). 2012 family friendliness index survey report of corporation and public institution.

Ministry of Gender Equality and Family(2013). Information brochure of 2013 best family friendly management.

OECD(2012). OECD year book 2012.

Pyeon, D.(2012). The refinement policy direction of a long-hour work. Korea Labor Institute, the Monthly Labor Review, the March issue of 2012.

Seoul Newspaper(2012). 16 working hours a day and so far as to weekend work - too much sweating shop of food industry. 2012. 8. 21., 10p.

Statistics Korea(2012). e-country index(http://www.index. go.kr/egams/index.jsp).

Statistics Korea(2012). Tentative result of third-quarter regional employment survey, National Statistical Office Press Release. 2012. 12. 26.

Statistics Korea(2012). The total use state result of 2012 flexible work arrangements, National Statistical Office Press Release. 2012. 8. 30.

The Cooperation of Related Ministries(2011). The $2^{\text {nd }}$ plan for healthy family.

Yang, H.(2011). The implementing actual condition and implication of small scale company's weekly fortyhour System. e-KIET Information of Industrial Economy No.523.

http://workfamily.sas.upenn.edu/site/workfamily.sas. upenn.edu/files.

http://ffm.mogef.go.kr/business/reviewCompany.do.
접 수 일 : 2013년 05월 15일

심 사 일 : 2013년 06월 03일

게재확정일 : 2013년 08월 15일 